\title{
Type 2 Helper Cell
}

National Cancer Institute

\section{Source}

National Cancer Institute. Type 2 Helper Cell. NCI Thesaurus. Code C12540.

Type 2 Helper Cells are a subset of helper-inducer T-lymphocytes which synthesize and secrete the interleukins IL-4, IL-5, IL-6, and IL-10. These cytokines influence B-cell development and antibody production as well as aug menting humoral responses. 